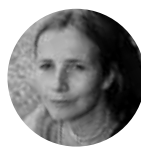

Ellen Lykke Trier, fagsykepleier ved Peer Gynt Helsehus

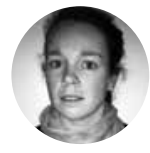

Camilla

Jørstad, intensivsykepleier ved Intensiv, Sykehuset Østfold, tidl. ansatt ved Peer Gynt Helsehus

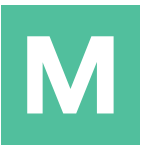

unntørrhet og munnstell er forsømte områder hos multisyke gamle og døende i kommunehelsetjenesten. Pleiepersonalet trenger kunnskap for å identifisere munntørrhet. Å lytte til pasientenes ønsker samt sørge for at munnstell inngår i daglige rutiner er viktig.

BAKGRUNN. Med anstrengt økonomi blir kompetansehevende tiltak ofte salderingsposten i kommunehelsetjenesten. «Frie midler» fra fylkesmannen i Østfold ga Peer Gynt Helsehus mulighet til å gjennomføre prosjektet «Munnstell hos alvorlig syke og døende - best practice». Samarbeidsprosjektet mellom den fylkeskommunale tannhelsetjenesten i Østfold og Peer Gynt Helsehus i Moss pågikk i ni måneder og ble avsluttet 1. oktober 2013. Utviklingssenter for sykehjem og hjemmetjenester i Østfold hadde oppfølgingsansvar for prosjektene finansiert av «Frie midler» i samarbeid med Fylkesmannen.

MUNNTØRRHET. Dagens sykehjemspasienter har i gjennomsnitt 6,5 diagnoser, bruker 7,2 legemidler fast, bor på sykehjemi 2,1 år og har en gjennomsnittsalder på 82 år (1). Dette viser at pasientene som får plass på sykehjem i dag er alvorlig syke.

Nasjonalt handlingsprogram med retningslinjer for palliasjon i kreftomsorgen (2) oppgir at inntil 80 prosent av dagens alvorlig syke og døende er plaget av munntørrhet. Munntørrhet skyldes ofte polyfarmasi og kroniske sykdommer og fører lettere til infeksjoner i munnhulen (3). De samme pasientene har også svekket immunforsvar, og mikrober kan da lett finne vei via blodbanen og gi pasienten et langt verre sykdomsbilde. Ivaretakelse av god munnhygiene er derfor infeksjonsforebyggende $(3,4)$.

STORE FORSKJELLER. Våre erfaringer er at munnstell ikke utføres systematisk til sykehjemspasienter og er heller ikke individuelt tilpasset. Vi ser store forskjeller i praksis bare ved samme virksomhet. Vi håper denne artikkelen fører til økt bevisstgjøring av utfordringer vedrørende munntørrhet og betydningen av godt munnstell uavhengig av hvor pasientene befinner seg i «systemet».

Munntørrhet er den subjektive følelsen av tørrhet i munnen på grunn av nedsatt spyttutskillelse (2). Munntørrhet kan utløses av dehydrering, medikamenter, manglende bruk av tyggemuskler, munnpusting, stress og feber. Dette kan føre til sprekker og sår i munnslimhinnen som blir en inngangsport for patogene mikroorganismer $(3,5)$.
MUNNSTELL. Et godt munnstell til eldre kan følge følgende skjema $(3,6)$ :

- Fukting av lepper

- Fjerne bakteriebelegg fra tannoverflater og gommer

- Rengjøring av tunge

- Rensing av slimhinner

- Smøring av munnhule

- Fukting av lepper

- Tenner og tannkjøtt inspiseres under hele prosedyren

Hensikten med et munnstell er å fjerne plakk på tenner og i munnhulen samt å forebygge tannkjøttsykdommer og tannråte. Litteraturen anbefaler å starte og avslutte hvert munnstell med leppepomade (6). Hos pasienter med egne tenner, rengjøres tennene med en myk børste; for eksempel barnetannbørste, med tannkrem uten såpestoffer. Hos pasienter uten egne tenner, kan også munnhulen pusses med samme børste og eventuelle tannproteser rengjøres ved hjelp av en protesetannbørste og vanlig håndsåpe (3). Tungen kan rengjøres med en tannbørste eller en tungeskrape.

SMøRES. Etter at tenner og slimhinner er renset for bakteriebelegg, matrester og slim, smører man hele munnhulen for å bevare et fuktig og beskyttende miljø, dette vil hindre uttørring. Dette punktet er spesielt viktig hos pasienter med munntørrhet og hos munnpustere
Fakta

Hoved-

budskap

Inntil 80 prosent av dagens alvorlig syke og døende er plaget av munntørrhet. Munntørrhet skyldes ofte flere medikamenter og kroniske sykdommer og fører lettere til infeksjoner i munnhulen. De samme pasientene har også svekket immunforsvar, og mikrober kan da lett finne vei via blodbanen og gi pasienten et langt verre sykdomsbilde. Ivaretakelse av god munnhygiene er derfor infeksjonsforebyggende.

Nøkkelord.

Les mer og finn litteraturhenvisninger på våre nettsider.

- Kronisk sykdom

- Palliasjon

- Munnstell

- Immunforsvar 


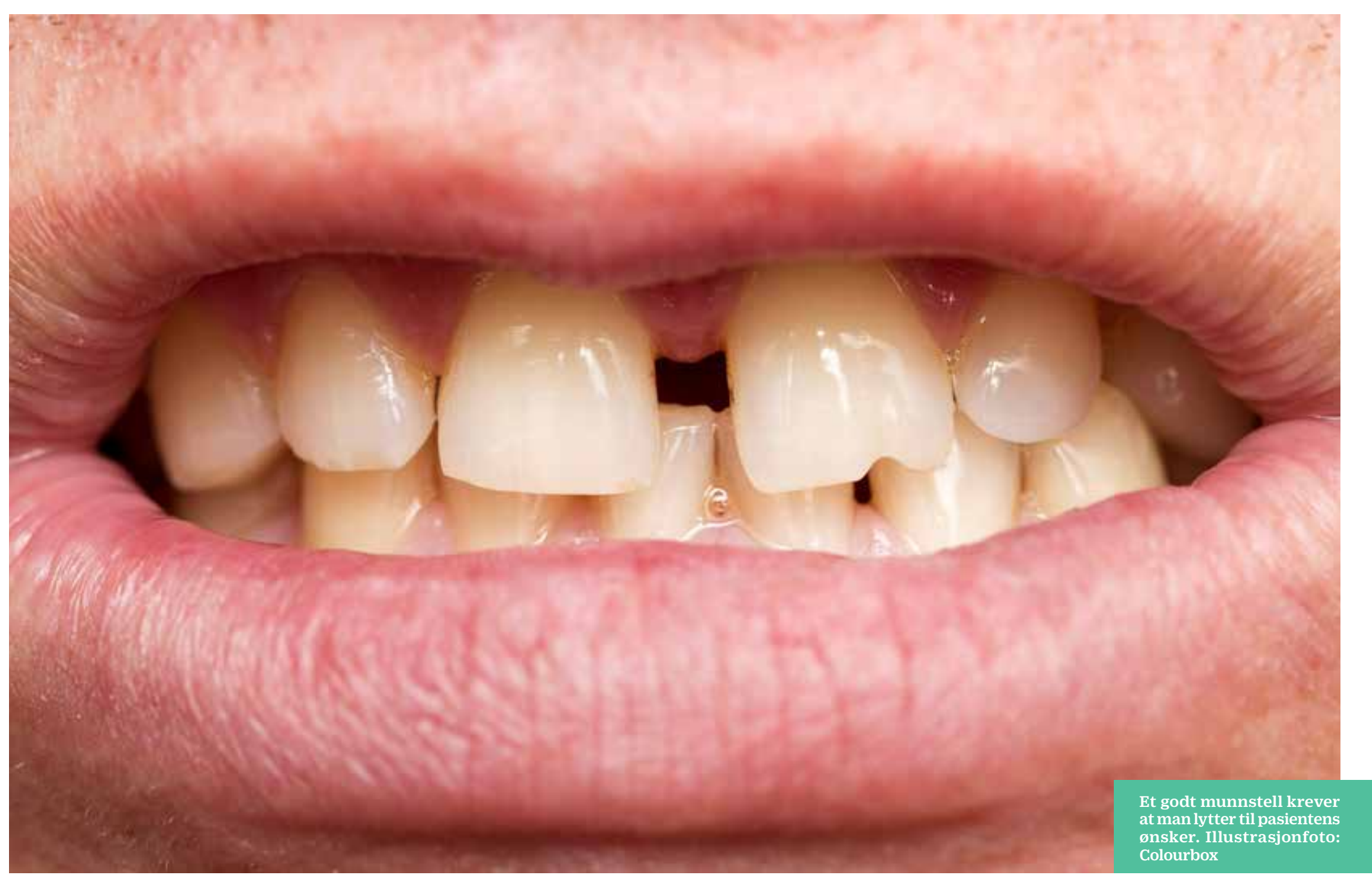

(7). God munnhygiene er med på å bidra til god kommunikasjon og opprettholdelse av et sosialt liv. Det stimulerer til bedre inntak av mat og drikke (6), bidrar til å bevare tennene og gir økt velvære (8).

Praktiske hindringer for et godt munnstell kan være ufaglært personale, dårlig tilgang på utstyr, fysisk motstand fra pasienten og stor gjennomtrekk av personale slik at munnstell ikke blir prioritert. De sosiale hindringene er like viktige som de praktiske. Munnstell kan sette pasient og personale i forlegenhet; det blir for intimt, personalet kan ha dårlig selvtillit med hensyn til utføring av munnstell, personalet har ikke tid og pasienten ønsker ikke hjelp til munnstell (9).

KJENT PROBLEMSTILLING. På lindrende enhet ved Peer Gynt helsehus er tilpasset munnstell en viktig sykepleieoppgave. Blant annet benytter man kartleggingsverktøyet ESAS (Edmonton Symptom Assesment System) for å identifisere ulike symptomer, inkludert munntørrhet, så tidlig som mulig (9). Munntørrhet er et symptom som sykepleierne ved Lindrende enhet møter ofte og som de har kunnskap om. Prosjektets mål var å heve kunnskapsnivået om munnstell og lindring av munntørrhet også ved de andre avdelingene ved Helsehuset, og ved de andre sykehjemmene og bo- og servicesentrene i Moss

\section{«Testingen $\mathbf{i}$ seg selv skapte interesse blant de ansatte.»}

kommune. Ved å legge prosjektet til andre enheter enn Lindrende enhet, ønsket man å involvere de ansatte der og styrke deres kompetanse gjennom å delta i prosjektet og ved å utarbeide et undervisningsopplegg.

Prosjektgruppen ønsket å fokusere på brukermedvirkning og inviterte derfor pasientene til aktivt å delta i prosjektet. Gruppen var også opptatt av pårørendes mulighet til å delta for eksempel gjennom å fukte munnen til den døende.

PROSJEKTET. Alvorlig syke og døende var målgruppen for prosjektet, men produktutprøving på døende var utelukket. Vi valgte derfor å ta utgangspunkt i alvorlig syke 
pasienter som var samtykkekompetente, og som ønsket å delta i undersøkelsen.

Alle deltakere fikk skriftlig informasjon om prosjektet og skrev under på samtykkeskjema i forkant av prosjektuken. Vårt opprinnelige mål om å inkludere 20 pasienter i produkttestingen ble en praktisk utfordring. Peer Gynt Helsehus er et «korttidssykehjem», hvor bare 12 av 53 senger er såkalte langtidsplasser. Vi ble til slutt nødt til å se oss tilfredse med fem pasienter fra fire forskjellige enheter. Kriteriet om at alle pasientene måtte være innlagt i hele prosjektuken ble vanskelig å innfri på et helsehus med rask rullering av plassene.

PRODUKTTESTING. Tannpleier underviste prosjektgruppen og ansatte på Helsehuset om konsekvenser av dårlig tannpleie og munnstell i forkant at prosjektuken. Prosjektuken startet opp med møter med hver enkelt pasient som hadde samtykket i å delta. Pasientene fikk utdelt en produktpakke (se faktaboks s. XX) og de fikk skriftlig og muntlig informasjon om pakkens innhold, og instruksjon om hvordan de skulle bruke produktvurderingsskjemaet. Sykepleier ba pasienten angi grad av munntørrhet ved bruk av ESAS-skjema (9). Tannpleier undersøkte pasientene og vurderte munntørrhetsgrad ut fra en beleggog slimhinneindeks (BSI)(10). I etterkant utarbeidet tannpleier et munnstellkort (11) til hver pasient.

Ansatte ble informert og bedt om å følge opp produktutprøvingen i tillegg til tannpuss to ganger daglig med tannbørste og tannkrem fra munnstellpakken. Produktutprøvingen foregikk over en arbeidsuke. Tannpleier og sykepleier gjorde nye vurderinger av munntørrhet siste prosjektdag. De innsamlete vurderingsskjemaene ble summert opp og svarene diskutert i prosjektgruppen.

RESULTATER. Pasientenes subjektive opplevelse av munntørrhet varierte fra 0 til 8 (hvor 0 er ingen munntørrhet og 10 er verst tenkelige munntørrhet). Tannpleierens vurdering stemte i høy grad overens med pasientenes subjektive opplevelse. Tannpleieren benyttet en belegg- og slimhinneindeksskala (BSI) hvor belegg angis på en skala fra 1-4 hvor 1 er intet synlig belegg og 4 er rikelig. SI slimhinneindeks angis fra 1 som betyr normalt og 4 som angir sterk inflammasjon (10).

Når det gjaldt endringer i grad av munntørrhet fra prosjektets første dag til prosjektets siste dag var det marginal bedring. Pasientenes tilbakemelding var at mange av produktene hadde effekt der og da, men at langtidseffekten var liten.

PRODUKTUTPRøVING. På bakgrunn av pasientenes tilbakemeldinger og de ansattes erfaringer anbefaler prosjektgruppen at man gjør visse endringer i innkjøp ved vår virksomhet. For eksempel kjøper vi inn spyttstimulerende sukkerfrie drops og sugetabletter, da pasientene ga uttrykk for at de hadde sterkere smak og var bedre enn de pastillene vi har i sortimentet i dag.

Flere av dem som var med opplevde at det var mange produkter å prøve ut, og at ikke alle produkter var like aktuelle for deres situasjon. Spytterstatningsmidler som gel eller spray samt munnpensler var det derfor ikke alle som prøvde.

Å gjennomføre en produkttesting i avdeling skapte i seg selv interesse blant ansatte på helsehuset. Siden pasientutvalget var så marginalt er det vanskelig å trekke konklusjoner som er valide for større grupper. Men enkelterfaringer fra prosjektet og pasientenes tilbakemeldinger ga viktig innsikt som vi blant annet kunne bruke i undervisningsopplegget vi utformet.

DISKUSJON. Vi ønsker til slutt å diskutere munnstell til døende på bakgrunn av våre prosjekterfaringer, fagprosedyrer og diskusjon med ansatte gjennom flere runder med undervisning i prosjektperioden.

LEPPEPOMADE. Vi vil anbefale leppepomade med E-vitamin. Den fikk gode tilbakemeldinger fra pasientene samt at vi fant at faglitteratur anbefalte vannbaserte fukteprodukter som inneholder vitamin E og kokosnøttolje, fordi de holder

«Produktene har kortvarig effekt mot munntørrhet.» lengre på fuktigheten (3) og ikke gir inflammasjoner (8). Hvit vaselin på tube som fordeles i begre og pensles på leppene med Q-tips er mye brukt i sykehjem. Det kan være økonomisk gunstig, men ut ifra et hygienisk perspektiv og det faktum at hvit vaselin er oljebasert, anbefaler vi pasienter å kjøpe nevnte leppepomade.

BELEGG. Desinfeksjon kan brukes hvis pasienten har belegg i munnhulen. Det er ulik praksis på om man skal benytte klorheksidin eller hydrogenperoksid. Klorhexidin er antiseptisk (3). Nasjonalt handlingsprogram med retningslinjer for palliasjon i kreftomsorgen framhever at klorheksidin inneholder sprit som kan gi svie og uttørking i munnhulen, og fraråder derfor bruk av dette til palliative pasienter. Vi anbefaler derfor ikke klorheksidin.

HYDROGENPEROKSID. Hydrogenperoksid 3 prosent er et annet desinfeksjonsmiddel som kan benyttes i munnhulen. Hydrogenperoksid danner oksygen når det kommer i kontakt med kroppsvæsker og effekten varer bare så lenge det frigjøres oksygen, så virketiden er kort. Hydrogenperoksid har effekt på de fleste vegetative bakterier.

I fagprosedyren «Munnstell til palliative pasienter» i Helsebiblioteket (7) anbefales Hydrogenperoksid tilsvarende en konsentrasjon på 0,5 prosent (Hydrogenperoksyd 3 prosent: $15 \mathrm{ml}$ i $75 \mathrm{ml}$ vann eller $\mathrm{NaCl}$ 9mg/ml). Hydrogenperoksyd har vi tidligere lest at man fraråder fordi det kan skade slimhinnen (3). Anne Watne Størkson (6) som har vært med å utarbeide prosedyren for Fagbiblioteket, understreker 
at det er viktig at man ikke lager for sterk konsentrasjon. Et mildere alternativ er bruk av lunken Salviete. Salvie har bakteriedrepende effekt (3) og brukes blant annet på Hospice Lovisenberg (12).

ARTERIEPINSETT. Thorsen et al. (7) anbefaler arteriepinsett med tupfer framfor munnpensler da de mener at engangspensler er for myke i skaftet og derfor egner seg dårlig. Vi velger allikevel ikke å anbefale bruk av arteriepinsett og tupfere ved munnstell da arteriepinsetten kan skade mucosa og tenner samt at tupferen kan (ved feil bruk av arteriepinsett) havne nedi pasientens luftveier (8). Ved bruk av arteriepinsett må man også påse at det benyttes ren arteriepinsett for hvert stell, og vi opplever ikke at det er ubegrenset tilgang på rene arteriepinsetter på sykehjem.

MUNNPENSEL. Det finnes ulike munnpensler, både fuktige og tørre, samt ferdige sett med tørre pensler og små poser med desinfeksjonsmiddel og fuktighetsgivende midler. Det er imidlertid viktig å huske på at munnpensler ikke fjerner plakk. Elektrisk tannbørste, eventuelt liten tannbørste med myk bust, bør derfor brukes til å pusse tenner så lenge pasienten er bevisst og kan samarbeide om dette.

Ineste fase kan munnpensler benyttes tilå fjerne mykt belegg, slim og matrester. Munnpensler brukes også til å fukte pasientens munn samt smøre på antimikrobisk stoff når tannbørste ikke kan benyttes (5). Vår erfaring er at munnpensel er et lett tilgjengelig engangsprodukt som kastes etter bruk og dermed gir god hygiene. På sykehjem er det mye ufaglært personale og bruk av låsbar pinsett og tupfere forutsetter mer opplæring. Det er også enklere for pårørende som ønsker å fukte munnen til døende å benytte munnpensler. Vi anbefaler derfor engangs munnpensler ved munnstell til døende.

SMØRE MUNNHULEN. Glyserol er et produkt man fortsatt finner på mange sykehjem og som mange fortsatt sverger til ved munnstell til døende. Glyserol har en fuktgivende og smørende effekt, men er omdiskutert. Glyserol har en osmotisk effekt som trekker til seg væske fra slimhinnene. På kort sikt kan glyserol gi en fuktig slimhinne, mens på litt lengre sikt kan den virke uttørrende (3). Thorsen et al. anbefaler blant annet glyserol, eventuelt med en smakstilsetning, men gjør oppmerksom på at Glyserol må brukes i riktig blandingsforhold, altså 17 prosent løsning. (7).

Ved vårt Helsehus har vi de siste årene forsøkt flere ulike spytterstatningsmidler i form av spray og geler (7) til å smøre munnhulen med. Våre pasienter som har prøvd disse midlene har ulike preferanser når det gjelder smak og konsistens, men er klare på at også disse produktene har kortvarig effekt mot munntørrhet.

FUKTING. Så lenge pasientene er bevisste kan ofte det å drikke små slurker vann, suge på isbiter, biter av ananas (7) eller suge på sukkerfrie drops, fluortabletter eller liknende være med på å holde munnhulen fuktig og motvirke plager av munntørrhet.

Døende som ikke lenger selv er i stand til ågjøre aktive tiltak og i tillegg puster gjennom munnen trenger derfor å få fuktet munnhulen ofte. Det er i den forbindelse viktig å huske på at pårørende som våker over den døende er en viktig ressurs. Å fukte munnen og smøre leppene til den døende kan oppleves som en meningsfull oppgave i ventetiden for familien, og ikke minst lindre munntørrhet og eventuelt tørstefølelse hos den døende (13).

KONKLUSJON. I litteraturen er det vanskelig å finne evidens for at et munnpleiemiddel er bedre en noe annet. Tilgjengelighet, brukervennlighet og pris bør derfor ha betydning for valgene man tar. Vi ser det står skrevet flere steder at det er selve handlingen munnstell som utgjør den store forskjellen for å lindre og forebygge munnplager! Å heve kompetansen, endre holdninger og innføre gode rutiner og prosedyrer for munnstell blir viktig! For å oppnå dette trenger vi å øke bevisstgjøringen omkring farene ved utelatt munnstell samt et sterkt engasjement i pleiegruppa for å gjøre det beste for pasienten.

Ideelt sett burde prosjektet vært gjennomført på et langtidssykehjem, og foregått over flere uker. Utfordringen består i å rekruttere nok samtykkekompetente pasienter i en tid hvor de fleste pasienter ved sykehjem har en eller annen form for kognitiv svikt.

I tillegg er det en stor utfordring å spre kompetanse og sørge for å opprettholde gode rutiner for munnstell i kommunehelsetjenesten når sykefraværet et høyt, vikarene mange og bruk av ufaglærte en del av hverdagen. Hyppig undervisning, god dokumentasjon og enkle prosedyrer som er lett forståelige for ansatte med dårlige norskkunnskaper, bør vektlegges.

Deltakerne i prosjektgruppen understreket betydning av det tverrfaglige samarbeidet og etablering av en tett kontakt mellom helsehuset og tannhelsetjenesten i kommunen som svært nyttig. Også muligheten til faglig fordypning og det å få nye utfordringer som viktig motivasjonsfaktor i en ellers krevende arbeidshverdag ble trukket fram.

\section{REFERANSER:}

1. Johannessen P. Nye kompetansebehov. Hvilken kompetanse må utvikles i sykehjem under samhandlingsreformen (Internettside). Oslo: Fylkesmannens helsekonfeanse 2012 http:/www fylkesmannen. De Dokument\%20FMOA/Hes sorgstjenester/Helsekonferansen $\% 202012 / \mathrm{Nye} \% 20$ kompetansebehov.pdf?epslanguage $=n b$ (Nedlastet: 12.11.13).

2. Helsedirektoratet. Nasjonalt handlingsprogram med retningslinjer for palliativ omsorg (Internettside). Oslo: Helsedirektoratet http://www helsebiblioteket no/ Retning

Retningslinjer/Palliasjon/Forord (Nedlastet: 24.10.13). . Flovik AM. Munnstell. Godt munnstell nodv
sebringende. 1. Utg. Oslo: Akribe, 2005.

4. McNally ME, Martin-Misener R, Wyatt CCL, McNeil KP. Crowell SJ, Matthews DC Clovis J. B. Action Planning for Daily Mouth Care in Long-Term Care: The Brushing Up on Mouth Care Program. Nursing Research and Practice. 2012 II sider. DOI: 10.1155/2012/368356.

5. Gulbrandsen T. Stubberud DG. Personlig hygiene og velvære. I: Stubberud, DG, red. Intensivsykepleie. 2. utgave. Oslo: Akribe, 2010: 94-126.

6. Watne Størkson A. Munnstell til palliative pasienter. Kreftsykepleie 20122:22-24

7elsebiblioteket. Munnstell til palliative pasienter. Bergen: Helse Bergen.http://www.helsebiblioteket.no/microsite/ fagprosedyrer/fagprosedyrer/munnstell-til-palliativepasienter (Nedlastet: 24.10 .13 )

8. Helse Møre og Romsdal. Hygienisk munnstell. Alesund: Helse Møre og Romsdal. http://www.helse-mr.no/ftp/ eqspublic/kompetanseportal/docs/doc_271/index.htm (24.10.13).

9: Helsebiblioteket. ESAS-Edmonton Symptom Assessment System (Internettside). Oslo: Helsebiblioteket. http:// Syww helsebiblioteket no/microsite/fagprosedyre// ww. -assessmentsystem (24.10.13).

10. Henriksen BM, Ambjørnsen E, Axéll T. Evaluation of mucosal-plaque index (MPS) designed to assess oral care in groups of elderly. Spec Care Dentist 1999; 19:154-7.

11. Dyvi EB. Klar bedring i tannstatus for eldre. Den norske tannlegeforenings Tidende 2003;113 (16): 854-55.

12. Sundal TE. Munnstell til alvorlig syke og døende. OMSORG 2012:2: 49-51.

13. Kaasa S. Væskebehandling hos pasienter med langtkommet kreft I: Kaasa S, red. Palliativ behandling og pleie. Nordisk lærebok. Oslo: Gyldendal Akademisk, 2006: 477-484.
Fakta 900

\section{Produlkt-utvalg}

Nasjonalt handlingsprogram med retningslinjer for palliasjon i kreftomsorg gir råd om hva et munnpleiesett bør bestå av. Basert på disse retningslinjene satte visammen følgende produktpakke, med noen produkter i tillegg:

- Tannpuss: Zendium tannkrem, tannbørste med myk og mindre bust, ACO-leppepomade med E-vitamin.
- Midler som stimulerer spyttproduksjon: Fluorette tyggegummi, Salivin fruktpastiller, Xerodrops og Xerodent sugetabletter.

- Spytterstatningsmidler: smøring av slimhimmer; Zendium gel, Salivia munnspray.

- Munnpensler: Toothette - tørr munnpensel, Ori Salivia - ferdig fuktet munnpensel. 